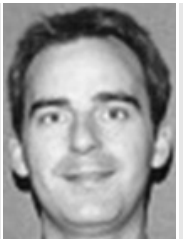

Paul A. Sanders Principal Engineer Flint \& Neill Partnership London, UK

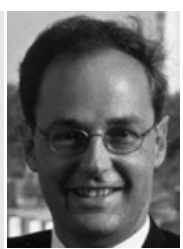

lan P. T. Firth Partner, Flint \& Neill Partnership, London, UK

\title{
Design and construction of the Sail Bridge, Swansea, UK
}

\section{P. A. Sanders BEng(Hons), ACGI, CEng, MICE and I. P. T. Firth MSc, DIC, CEng, FICE, FConsE, FIStructE}

This paper describes the design and construction of the Sail Bridge over the River Tawe at Swansea, South Wales. This pedestrian bridge represented a key element in the regeneration of the disused docks area, unlocking the potential for the new Port Tawe Innovation Village under development by the Welsh Development Agency. The development of the design and construction from planning stage through to completion of construction is discussed. This includes the selection of the bridge form along with the use of computer modelling techniques to develop the complex geometry, fabrication and bridge erection issues, aerodynamic investigations and the design of tuned mass dampers to control potential pedestrian-induced vibrations.

\section{INTRODUCTION}

The Sail Bridge (Figs 1 and 2) is one of two new pedestrian crossings connecting the city centre area to the new development on the east side of the River Tawe. Early in the development there was a strong desire to create a landmark structure to be a catalyst for the regeneration and to attract interest and investment in the area. The contribution of such landmark structures towards redevelopment projects is well established and is typified by projects such as the Gateshead Millennium Bridge.

The other new crossing, which is not discussed in detail in this paper, lies about $400 \mathrm{~m}$ downstream of the Sail Bridge, over the tidal barrage. It consists of two separate structures: a steel truss spanning $80 \mathrm{~m}$ across the weir and a $30 \mathrm{~m}$ opening bridge across the southern end of the navigation lock. This crossing, now known as the Barrage Bridge, connects the new development with the marina and proposed new housing close to the beach. The Sail and Barrage bridges are shown in the location plan (Fig. 3).

The bridges and new interconnecting walkway were procured under the NEC Engineering and Construction Contract (option Ctarget cost). Work commenced in September 2002 and the bridges were opened in June 2003, a remarkably short duration given the work involved. Flint \& Neill Partnership (FNP) was the engineer and project manager, and the steelwork contractor was Rowecord Engineering Limited (REL) of Newport, South Wales, which fabricated and erected all the steelwork on behalf of main contractor Balfour Beatty. The total cost of the two footbridges and walkway was $£ 4.25$ million (2003 prices), the Sail Bridge alone accounting for approximately £3 million. This sum is equivalent to about $£ 4300 / \mathrm{m}^{2}$ of deck area, which is very favourable when compared with other recent landmark bridges.

\section{PLANNING STAGE DEVELOPMENT}

The outline brief for the project was to provide the two bridges with a connecting walkway along the east bank of the river. Preferred alignments for the bridges were determined after consideration of existing links and proposed desire lines, visual preference and construction access. The Sail Bridge lies on the direct route from the city centre to the hub of the new development and connects to open areas on both banks of the river that are ideal spaces for future public development. Extensive discussions were held with interested parties in the preparation of the planning application. It is interesting to note that the original alignment conceived for the Sail Bridge would have resulted in a much shorter overall bridge length but resulted in landings that were considerably less appealing from the bridge users' perspective.

Key constraints in the development of the bridge form and the choice of steel for the superstructure were the limited budget, extremely tight overall programme, difficult working environment, $3 \mathrm{~m}$ tidal range and the need to minimise the risk of water pollution during construction. In addition the Environment Agency prohibited piling in the river in the period May to November to protect migratory salmon. In addition to the programme advantages, the selection of steel for the mast and deck offered the potential to maximise off-site prefabrication during a winter construction period at a site vulnerable to river flooding and exposed to the sea.

During the planning phase there was considerable concern about the vulnerability of the bridge to vandalism. While great care was taken to develop details that were as robust as possible it is interesting to note that in the two years since the bridge first opened there have been very few reported instances of vandalism, leading to the suggestion by some that the creation of a high-quality bridge has engendered a feeling of pride. This has been confirmed by feedback from the local community. 


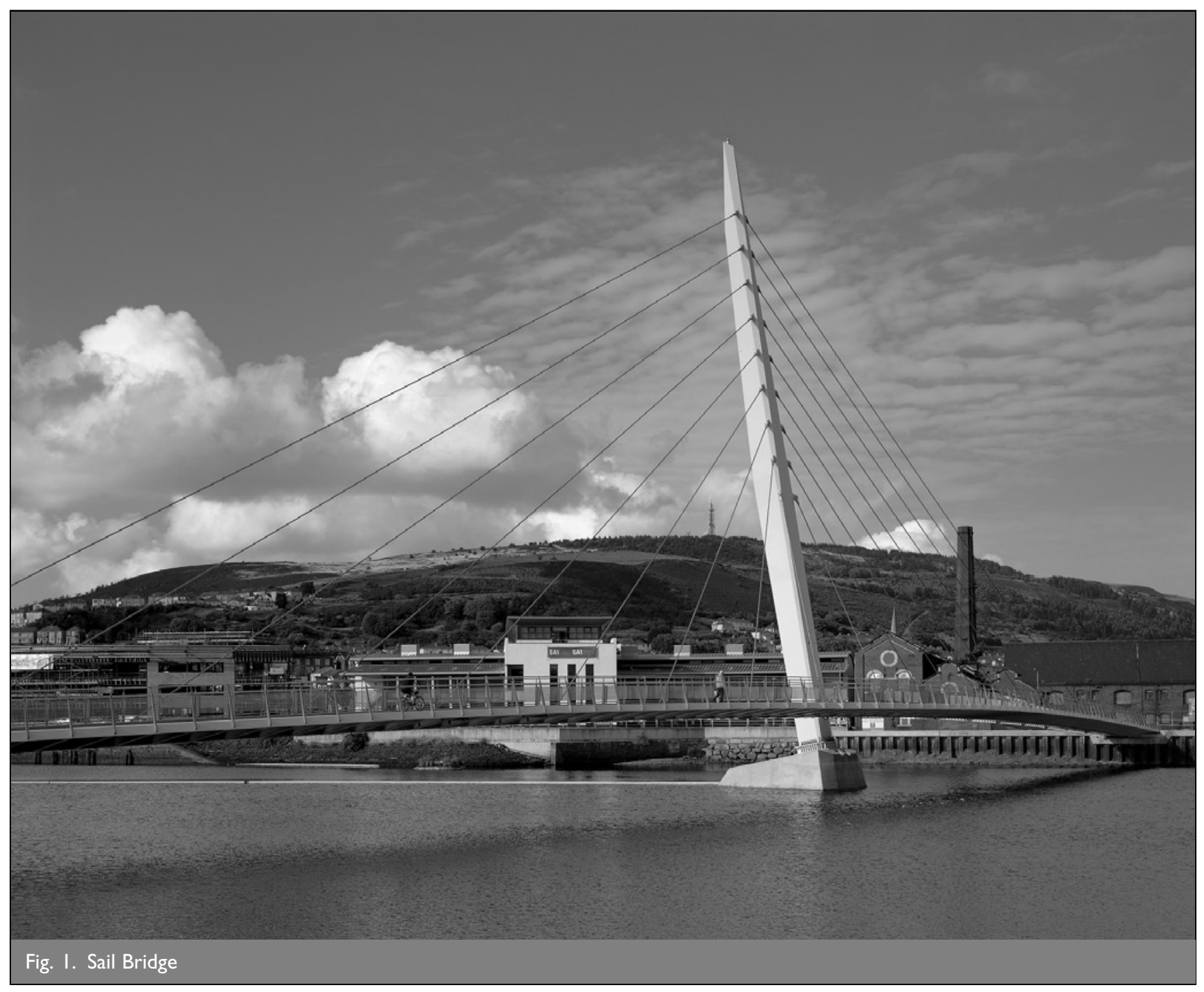

\section{DESIGN CRITERIA}

The bridge had to be designed to allow future adoption by the local authority, the City and County of Swansea (CCS). Among other things, this meant that the design had to comply with the relevant parts of the UK Design Manual for Roads and Bridges (DMRB). ${ }^{1}$ Some special criteria had to be adopted where the standard criteria were not strictly applicable, and some of these are discussed below, but on the whole the structures were designed in accordance with BS $5400^{2}$ and in particular with Part 3, the UK Code of Practice for Steel Bridges. ${ }^{3}$

Part of the conceptual design and the planning philosophy required that a special architectural lighting system should be used in addition to lighting provisions for bridge users. The lighting scheme was developed by the architect for the scheme, Wilkinson Eyre Architects. Furthermore, environmental constraints required that the bridge should not shed light directly down onto the water so as to avoid disturbing the migratory salmon.

\section{SAIL BRIDGE DESIGN}

The Sail Bridge is a $140 \mathrm{~m}$ long cable-stayed bridge with a single central mast with nine pairs of stays supporting the steel box girder along one edge. The vertical profile of the deck is asymmetric to suit the different levels at the abutments on the east and west banks (Fig. 4) and in plan the deck follows a sweeping curve over the central section (Fig. 5). A typical deck section is shown in Fig. 6. Gradients have been kept to be less than $1: 20$ to meet specified access requirements and, in order to keep the bearings above extreme high-tide level, this results in the need for a ramp up to the abutment on the west bank.

The trapezoidal box is only $800 \mathrm{~mm}$ in depth with a stiffened top flange and cantilevers and internal diaphragms typically at $1.55 \mathrm{~m}$ centres to coincide with parapet posts. All steel is grade S355 generally to BS EN 10025 with flange plates up to $30 \mathrm{~mm}$ thick. The box was detailed to be assembled upside down with the bottom flange forming the closing plate, so, apart from at stay diaphragms, the diaphragms are not welded to the bottom flanges. The deck box is relatively shallow and classified as a 'confined space' in terms of access requirements, it is therefore sealed to prevent ingress of water, and all services and equipment are kept outside the box obviating the need for internal access for maintenance. Any moisture that might collect internally is free to drain towards the abutments where an inspection hatch is located in the bearing diaphragm. The wide top flange has longitudinal flat stiffeners to deal with out-of-plane loads, which include concentrated wheel loads due to maintenance vehicles. The narrower bottom flange and web plates are generally unstiffened for economy of fabrication. 


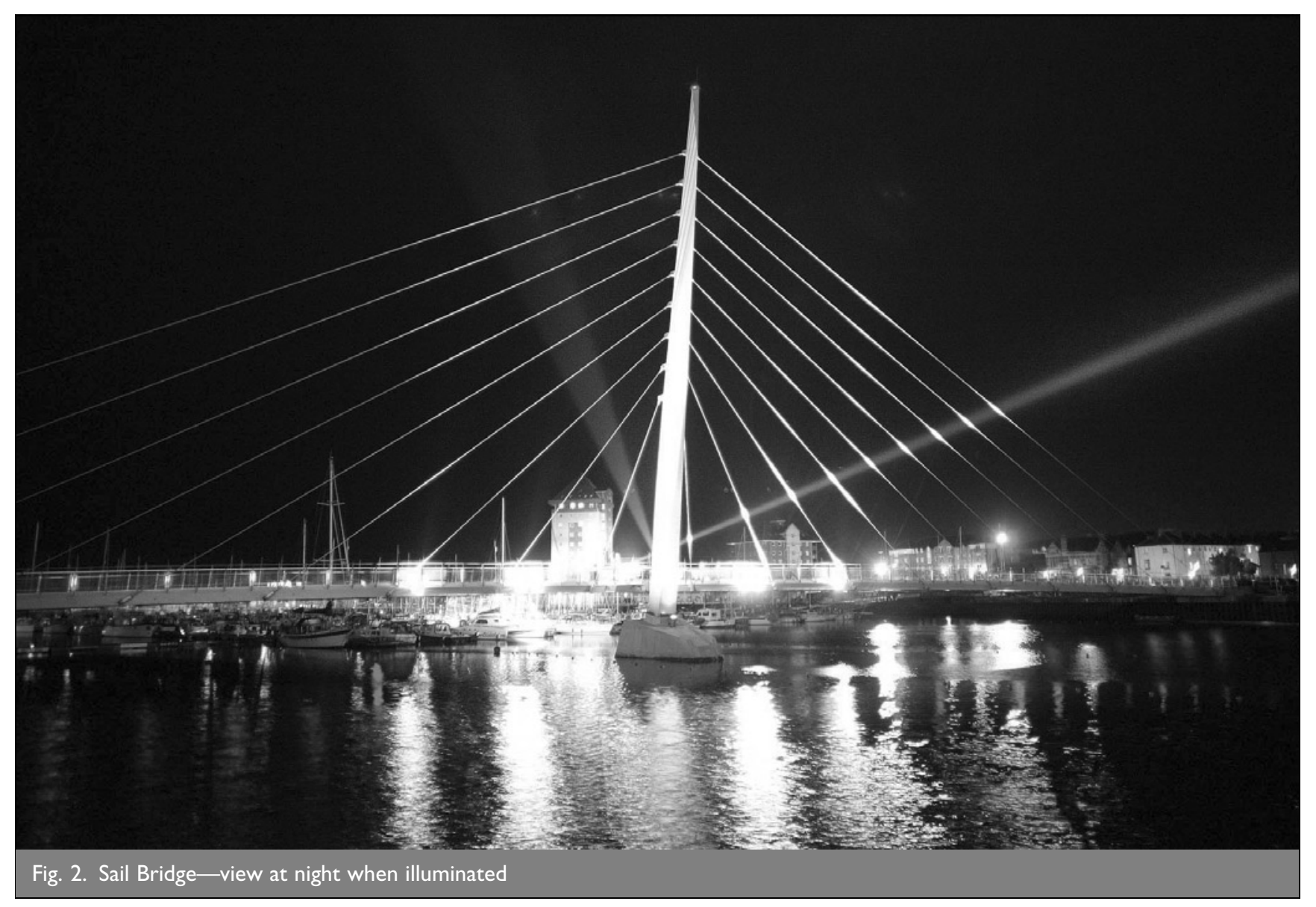

The longitudinal cantilevers support extruded aluminium sections which span transversely and are supported by angle stringers. The aluminium decking gives a distinctly different appearance to the deck and provides a lightweight solution. Even though the plank cross-section was unique and therefore required the manufacture of a new extrusion die, the aluminium decking proved to be an extremely economical solution.

Great care was taken over the detailing of the parapets which are almost entirely made from stainless steel. Although more expensive than conventional parapets, they are robust and hard wearing and minimise long-term maintenance requirements. Both parapets are $1.4 \mathrm{~m}$ high, the minimum required for cycle bridges in the UK. The upstream parapet consists of a special wedge wire mesh. Lighting units incorporated within the posts at $4.8 \mathrm{~m}$ intervals provide lighting intensities appropriate for safe night-time use. The downstream parapet consists of a simple tensioned wire system. The use of stainless steel introduces potential problems associated with the use of dissimilar metals in contact. However, the support lugs, which are made from stainless steel, are welded directly onto the deck box thus minimising the need for more complicated insulated bolted connections elsewhere in the post itself. Electrical power supply was routed on the external face of the downstream web of the deck box, hidden from view but accessible for future maintenance, with cable ducts passing through the deck in sealed tubes to the lighting units on the upstream edge.

The entire bridge geometry was developed using three-dimensional, solid modelling software. In addition to being an invaluable tool for developing the complex geometry, the bridge model was rendered and colour photomontage images produced. These images, which were available for the preparation of the planning application and the consultation process, assisted with the rapid promotion of the scheme and demonstrated the enormous benefits that this type of tool can bring to a project of this nature.

The $44 \mathrm{~m}$ high steel mast is inclined upstream at $10 \cdot 3^{\circ}$ and consists of plates up to $45 \mathrm{~mm}$ thick all in grade S355 steel. The inclination and transverse offset of the mast from the deck was selected to ensure that there were minimal transverse bending effects in the mast under permanent loads. The mast shape was developed using three-dimensional, solid modelling software, and in spite of its apparent complexity the shapes were all derived to facilitate fabrication. The front plate is curved in section, being cut from a large diameter cylinder, and all of the other plates are flat, avoiding any warped surfaces. At the suggestion of the fabricator, the sharp upstream edge in the upper part of the mast was achieved using a long, solid-machined triangular section to good effect. Mast designs were developed both with and without longitudinal stiffeners, and the heavier arrangement without longitudinal stiffeners was adopted since this resulted in a considerable overall saving, even allowing for the additional cost of the heavier crane required. Where the upper mast section becomes too small to permit internal access during assembly it is detailed such that the curved front plate is the closing plate (Figs 7 and 8)

The base of the mast is stressed onto a steel plate fixed to the pier by a group of 40 and $50 \mathrm{~mm}$ diameter high-tensile bars to form 


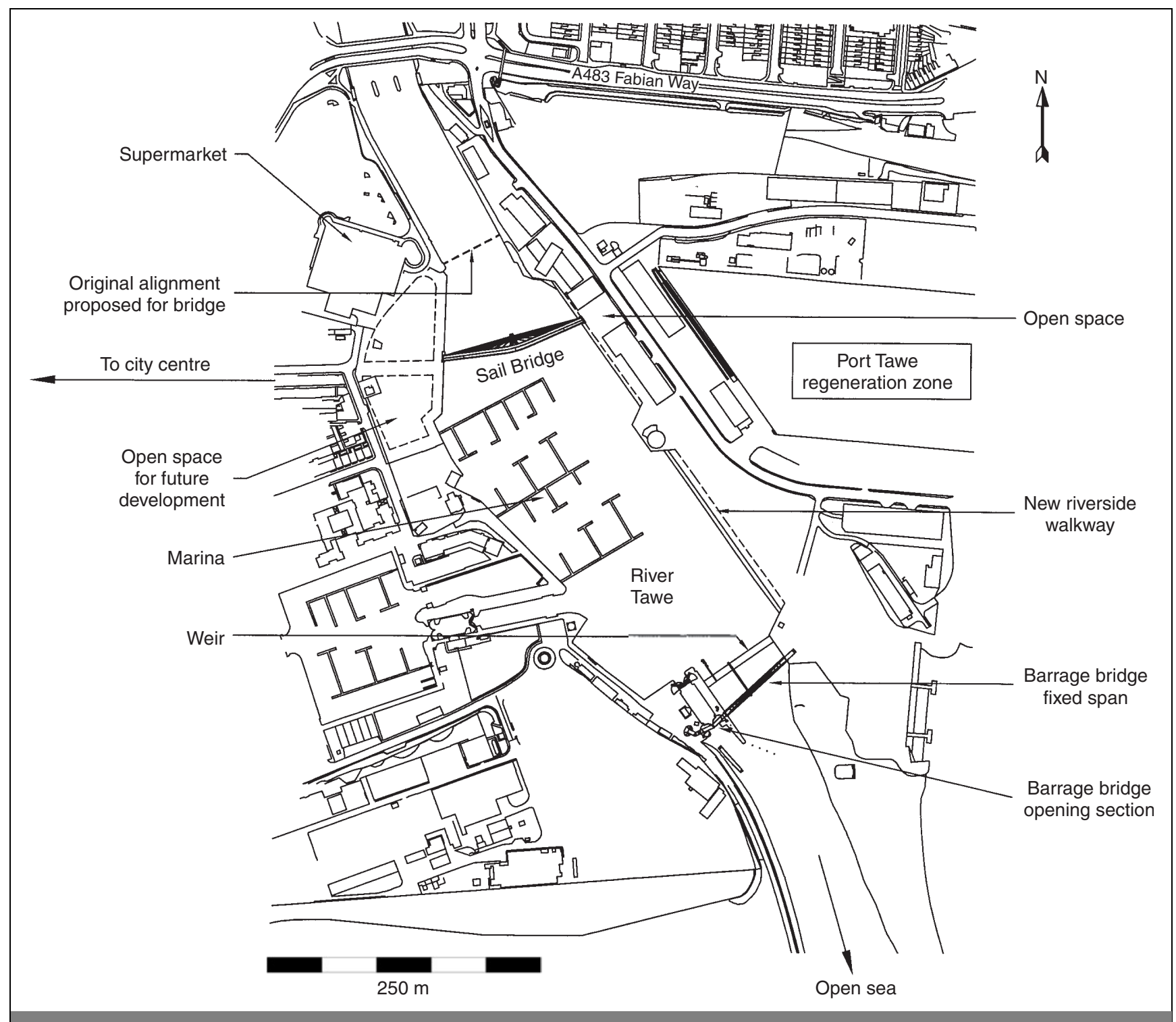

Fig. 3. General location plan

a full moment connection. The bars are located inside steel void former tubes and rigidly supported in a frame cast inside the pier. Tight tolerances were specified for setting the frame in position as small angular errors result in significant deviations at the top of the mast. Some facility for secondary adjustment was permitted by providing a $25 \mathrm{~mm}$ thick grout layer below the base plate set on the pier. After stressing the bars to $700 \mathrm{kN}$ the void formers were grouted to provide corrosion protection to the prestressing bars.

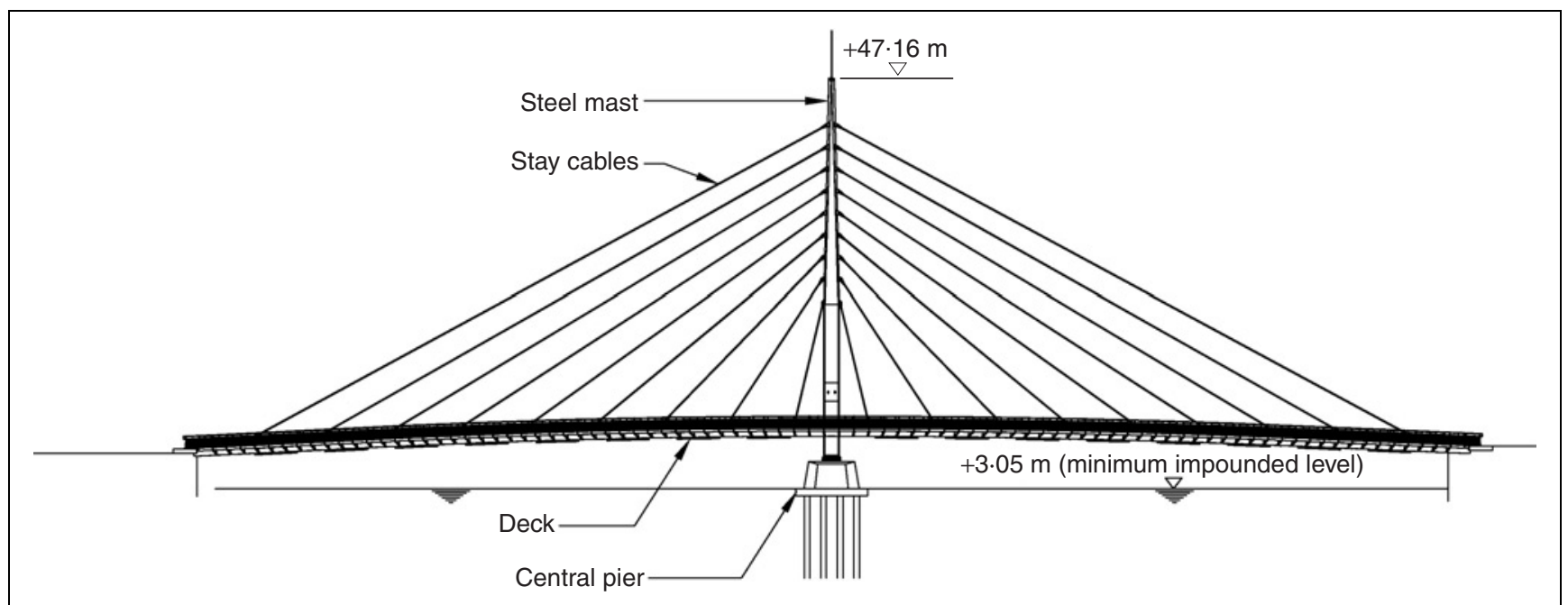

Fig. 4. Elevation on Sail Bridge 


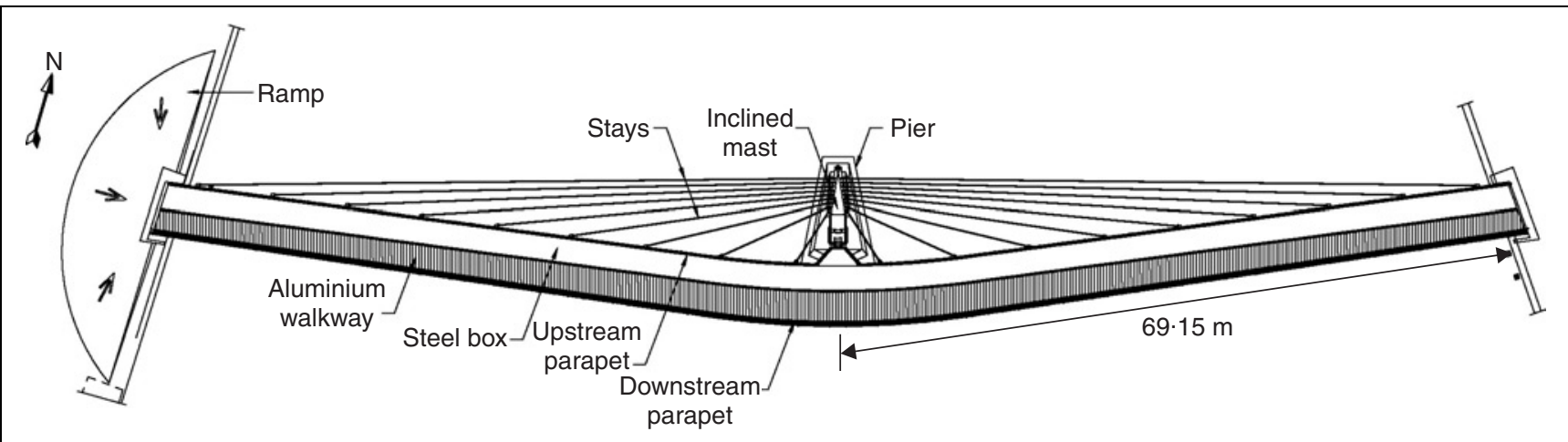

Fig. 5. Plan on Sail Bridge

The deck is supported vertically, torsionally and laterally at both abutments. The eccentricity of the cables from the shear centre of the deck results in significant torsional moment in the deck, which are transferred to the abutments via conventional pot bearings both of which stay in compression under service loads. This is achieved by configuring the end diaphragm with outriggers as shown in Fig. 9. At the centre, the deck reacts against the mast through a specially designed spherical bearing to allow rotation in all directions. Torsional restraint of the deck at this point is provided due to the eccentricity between the stays and the bearing. As a result the two pairs of stays closest to mast carry significantly higher loads than the other stays. This unusual articulation creates an apparent precariousness adding drama to the experience of crossing the bridge. Facilities were incorporated in the design for replacement of all bearings via provision of suitable jacking points including a temporary hold-down detail at the centre bearing to tie the deck down to the pier beneath during bearing replacement.

The cable stays are $60 \mathrm{~mm}$ diameter spiral strands with clevis pin terminations at the mast end and adjustable threaded cylindrical sockets at the deck end. In order to simplify the setting of the anchorage tube at the correct angle to the deck during fabrication, the anchorage steelwork consists of two circular hollow sections welded together, with one passing right across the width of the box (Fig. 10). Nevertheless, in order to achieve accurate angular setting of the stays relative to the anchor steelwork and avoid potentially damaging stay-bending effects at the neck of the socket, twin circular tapered washers were also provided behind the bearing nut to provide variable angular adjustment of up to $\pm 2 \cdot 5^{\circ}$ in any direction. The bridge is designed to permit the controlled replacement of any one stay without the need for additional temporary supports to the deck.

Finally, an architectural lighting scheme was developed comprising up-lighters to illuminate the mast and stays. The up-lighters were located on the upstream web of the deck in a location accessible for future maintenance.

\section{DYNAMIC BEHAVIOUR}

At the initial stages, a desk study was undertaken to determine the aerodynamic performance of the bridge in accordance with BD49. ${ }^{4}$ This was followed by a programme of wind tunnel tests on a $1: 15$ scale section model of the deck and a $1: 25$ scale model of the mast to examine potential vortex shedding, galloping and flutter behaviour.

The vortex-shedding responses of the deck were measured in smooth flow for bending and torsion modes. Measurements were made for angles of wind incidence of $-5^{\circ}, 0^{\circ}$, and $+5^{\circ}$ for two levels of structural damping (logarithmic decrement values of 0.03 and 0.05 ) and for winds approaching the deck from both directions. Aerodynamic derivatives were also evaluated. To account for scale effects and uncertainties, tests were undertaken on full-scale sample sections of the upstream parapet wedge wire infill panel to measure the pressure drop across the barrier. Etched brass strips with equivalent solidities were then made to replicate the same full-scale behaviour and used in the scale model tests.

Because of programme constraints these tests were necessarily undertaken after fabrication had commenced. The tests identified potentially unacceptable vortex-induced vibrations of the deck section with the wind incident on the upstream face of the deck box at a wind speed of between 12 and $14 \mathrm{~m} / \mathrm{s}$. Additional tests 


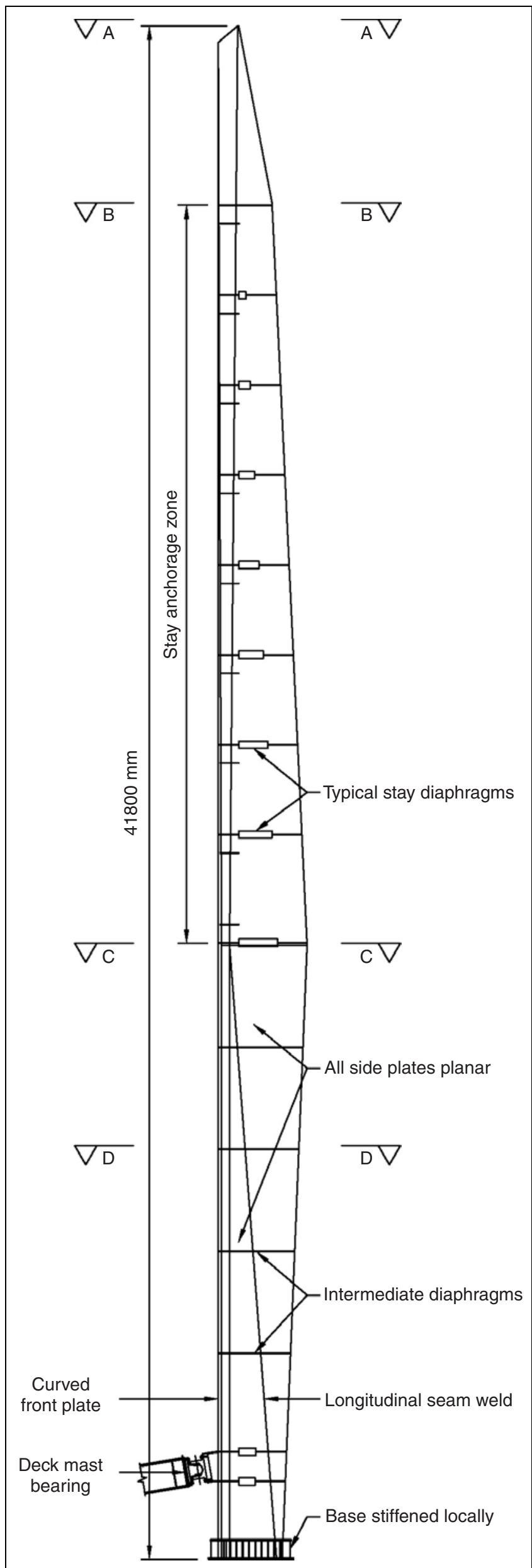

Fig. 7. Side elevation on mast
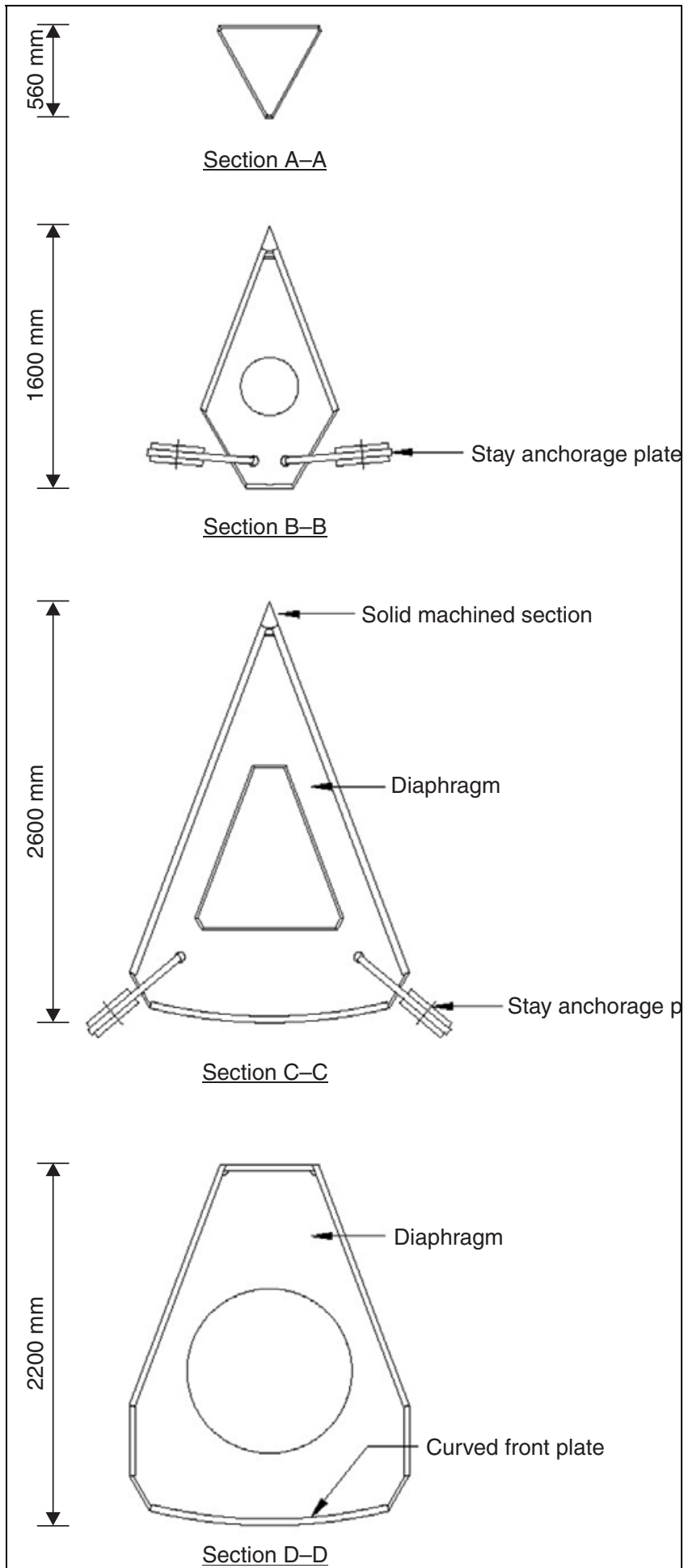

Fig. 8. Sections through mast

were rapidly instigated to evaluate the effectiveness of a range of aerodynamic devices to improve the flow around the box. These tests showed that a simple bent splitter plate at the bottom leading edge of the box substantially improved the performance. The final solution is shown in Figs 6 and 11. A torsional instability was predicted to occur at a wind speed of $45 \mathrm{~m} / \mathrm{s}$, but this was considered to be acceptable as it is considerably above the required threshold.

The aerodynamic performance of the mast was assessed in smooth flow in terms of both divergent instability and 


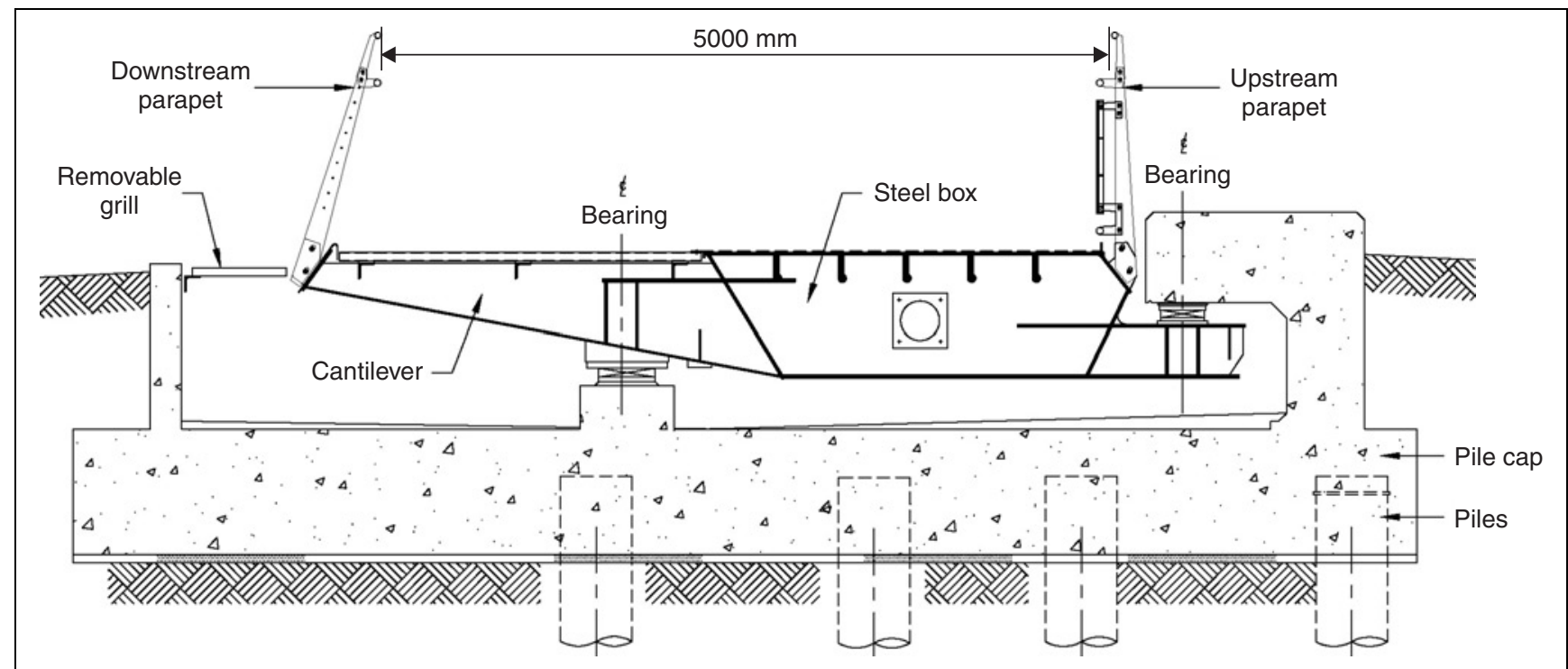

Fig. 9. Elevation on abutment showing bearing orientation

vortex-shedding response. A very small vortex-shedding response was found in one particular direction of incidence at low damping with a wind speed of $20 \mathrm{~m} / \mathrm{s}$, but this was judged to be acceptable. No divergent instabilities were found.

Dynamic analysis of the bridge predicted a first vertical mode at a frequency of $0.93 \mathrm{~Hz}$. A time history analysis was undertaken to determine vertical deck accelerations due to pedestrian action assuming a sinusoidal varying synchronous point load with a peak value of $180 \mathrm{~N}$ in accordance with BD37. ${ }^{5}$ This analysis showed that the predicted vertical accelerations were considerably less than the specified limiting value of $0.48 \mathrm{~m} / \mathrm{s}^{2}$. Investigations undertaken to determine the vertical response due to joggers and groups of pedestrians also indicated satisfactory performance.

Following the events of June 2000 when the new London Millennium Bridge was opened to pedestrians and promptly closed again because of excessive transverse vibrations, FNP was commissioned by the designer of that bridge, Arup, to assist in the investigation and development of appropriate remedial measures to solve the problem. ${ }^{6}$ As a result of that work and other studies carried out by the practice, FNP was well placed to advise

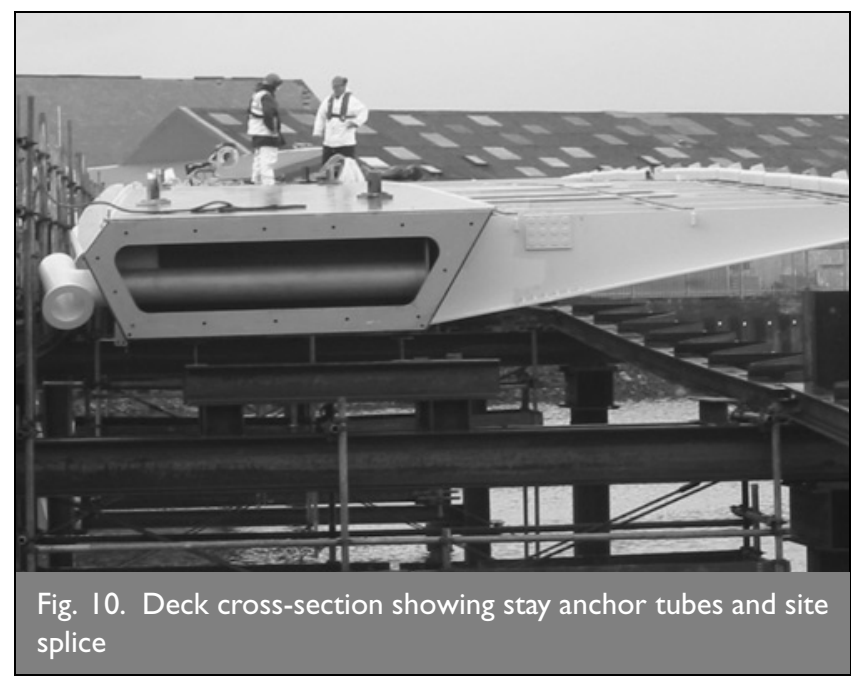

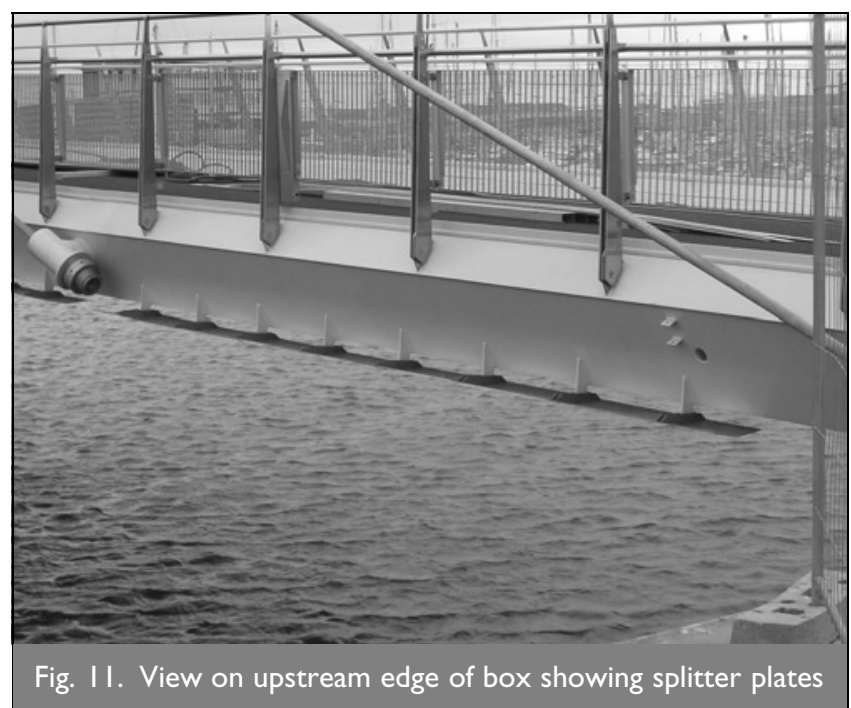

on the adoption of suitable criteria to prevent such occurrences on the Sail Bridge.

The first transverse horizontal mode was found to be $1.22 \mathrm{~Hz}$ (see Fig. 12). Analysis showed that the crowd-loading intensity

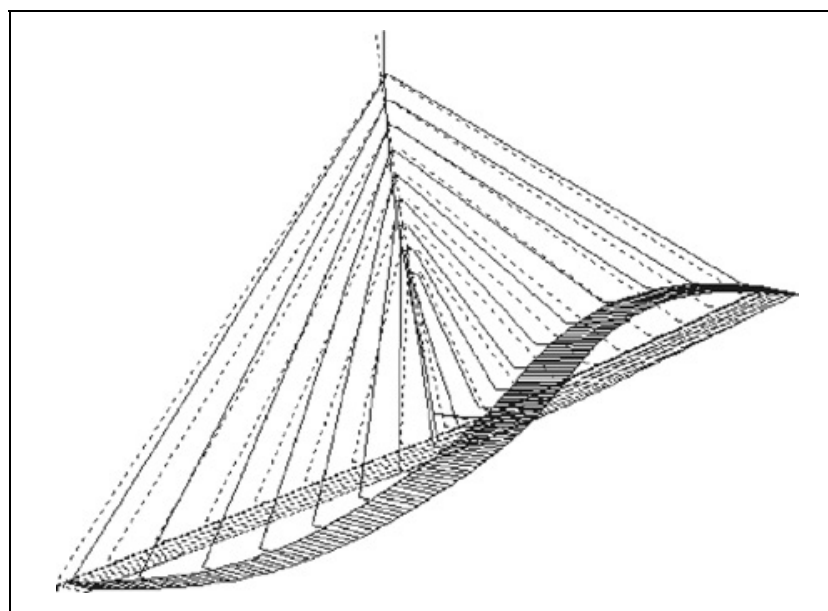

Fig. 12. First transverse mode at frequency of $1.22 \mathrm{~Hz}$ 


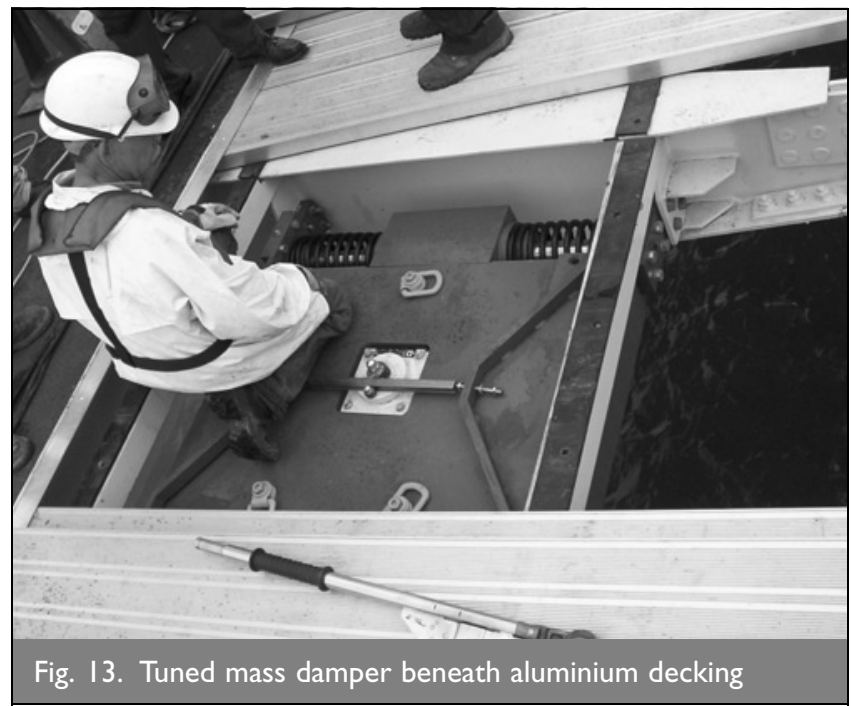

necessary to trigger transverse 'lock-on' response to pedestrian action had a reasonable probability of occurrence at this site, so the decision was taken to install transverse-tuned mass dampers (TMDs) to control the response. The TMDs were designed and supplied by Maurer Söhne in collaboration with FNP. In order to keep the deck dampers accessible for ease of maintenance, the TMDs were located between the cantilevers under removable sections of the aluminium deck (Fig. 13). A total of four TMDs were provided, with pairs of dampers at the anti-node positions in the middle of each span. The total mass of the TMDs is $7 \cdot 6 \mathrm{t}$ representing approximately $4.6 \%$ of the generalised modal mass for the lateral mode in question. The overriding objective was to limit the maximum lateral acceleration to no more than $0.15 \mathrm{~m} /$ $\mathrm{s}^{2}$ under a pedestrian load equivalent to approximately $1 \cdot 2$ pedestrians $/ \mathrm{m}^{2}$. After installation, tests were undertaken to verify the actual frequency of the bridge and the performance of the dampers. Accelerometers were located on the bridge which was excited laterally using a fused pulling system attached to the quayside. These tests confirmed a good agreement with the predicted frequencies. These simple tests were rather crude in that they provided a transient point load impulse to the bridge deck, but they proved adequate and cost-effective when compared with alternatives. On the day the tests were undertaken strong gusting winds resulted in ambient vibrations which allowed the frequencies to be clearly identified from a Fourier transform analysis of the measured vibrations. This was fortunate as it gave several hours of recorded bridge movements and greatly improved confidence in the calculated frequencies.

\section{BRIDGE CONSTRUCTION}

Approximately 70\% of the overall value of the Sail Bridge construction costs were associated with the steelwork fabrication and erection. Early involvement of the fabricator, REL, greatly assisted in developing the design and details based on their particular experience. REL used the proprietary software package Xsteel to develop a three-dimensional model of the bridge, which, given the complexity of the geometry, proved to be an extremely accurate and efficient tool (Fig. 14). The software permitted the cutting profiles and weld preparation details for all individual plates to be defined, taking into account weld shrinkage and precamber requirements.

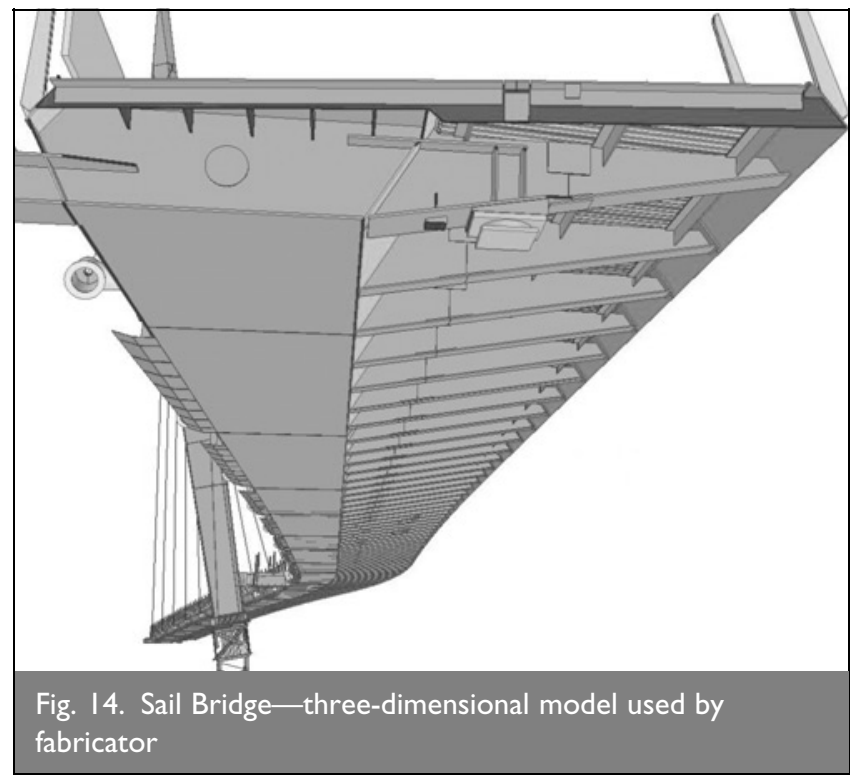

An erection strategy based on shop fabrication, transportation by road and erection by large-capacity mobile cranes was developed (Fig. 15). This resulted in the mast being prefabricated in four sections (Fig. 16), transported to site, welded together and erected as a complete $80 \mathrm{t}$ unit. Alternative erection methods were considered but the method chosen obviated the need for substantial temporary connections and welding at height. The main crane itself was delivered to site on over 40 lorries, took four days to assemble and incorporated a substantial 'superlift' counterbalance. This crane was positioned on the west bank to install the mast and approximately two-thirds of the total deck. The remaining sections of deck were installed from the opposite bank using a smaller mobile crane.

The deck was prefabricated in 11 units, checked for alignment and fit-up in the shop, transported to site and assembled into final position on a temporary piled trestle (Fig. 15). Site splices typically consisted of double diaphragms with match drilled bolt holes with welds formed from one side only using the edge of the diaphragm as a backing plate. Where internal access was required, a temporary hole was formed in the web under the cantilever (where it would be least conspicuous) which was later plated and welded. The total deck weight, including finishes, was approximately $1.9 \mathrm{t} / \mathrm{m}$, which amounts to $266 \mathrm{t}$ in total. Alternative methods of deck erection were considered, including the balanced cantilever technique, but these would have required the introduction of complicated pre-camber 'twists' because of the eccentric stay support and would have made geometric control extremely difficult.

The mast was lifted at a radius of approximately $80 \mathrm{~m}$, lowered over the holding-down bolts and held in position while the anchor bolts were stressed. The tension in the anchor bars was rechecked four weeks later before grouting the void formers.

Following completion of the deck the stays were installed and incrementally stressed to achieve the required alignment of the deck, at which point temporary packers supporting the deck could be removed. Stay loads were monitored throughout and found to compare well with the predicted values. Finally, the 


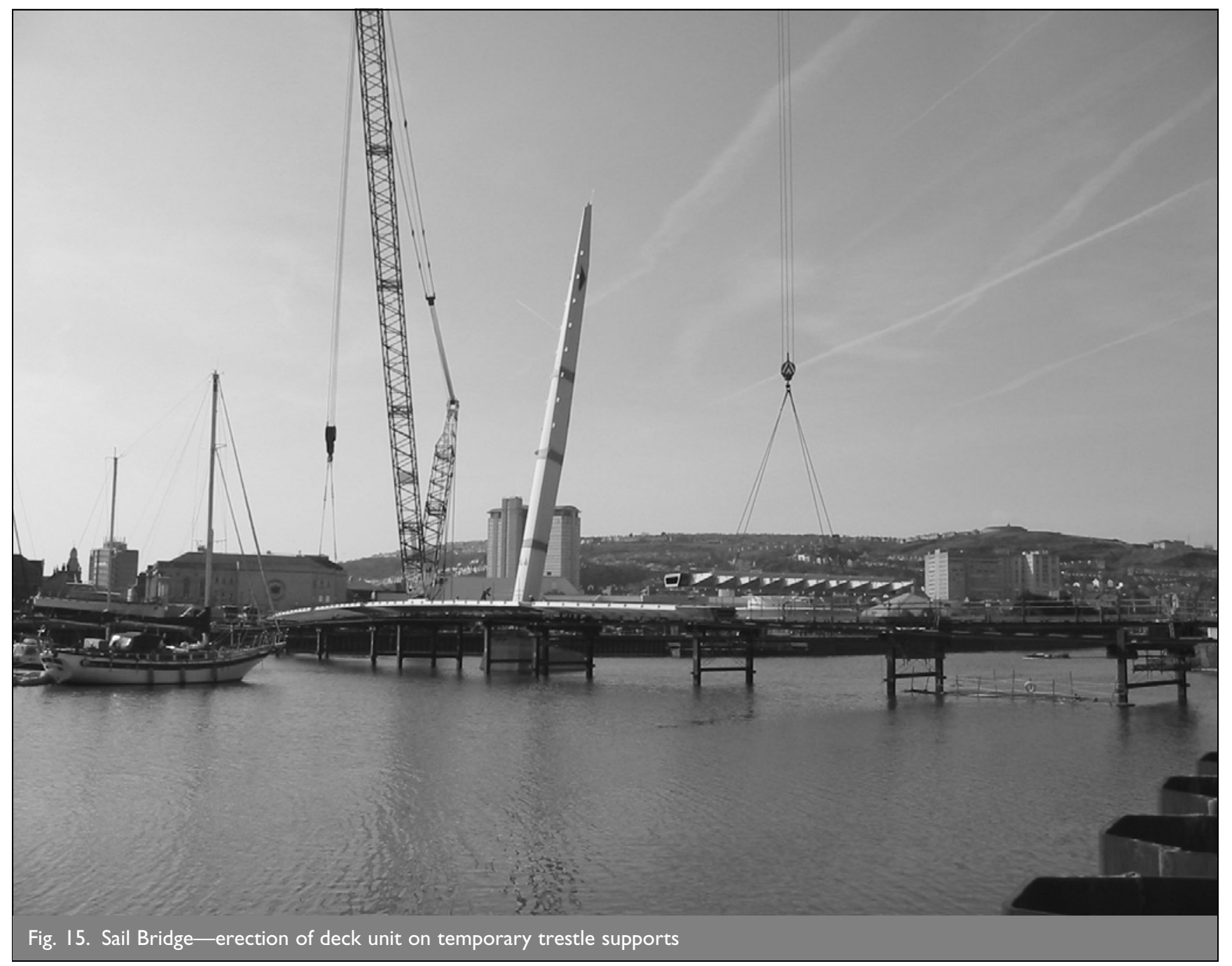

parapets which were detailed to provide for adjustment in both the horizontal and vertical directions were accurately aligned.

The main river pier consists of $600 \mathrm{~mm}$ diameter driven tubular steel piles supporting a reinforced concrete pile cap extending down to just below water level. As a cost-effective alternative to installing a conventional sheet pile cofferdam the pier was formed inside a steel hull sealed over the piles. Holes in the base of the hull were matched to the as-built pile positions (Fig. 17)

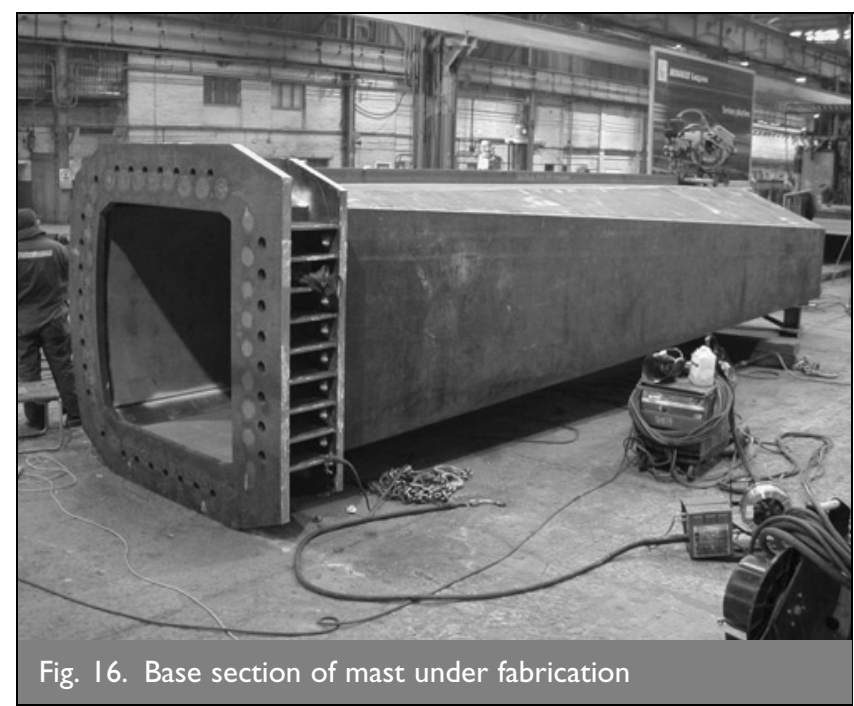

and the hull was assembled from prefabricated steel panels at high level supported by some of the piles which had been left over length. When the hull was lowered into final position rubber gaskets with jubilee clips were installed by divers to form a watertight seal between the piles and the hull. When pumped dry, the hull permitted construction of the concrete pier in a dry environment (Fig. 18). For economy the hull was designed to flood during extreme high tides which meant that concreting was timed to fit within the tidal cycle when lower high tides were

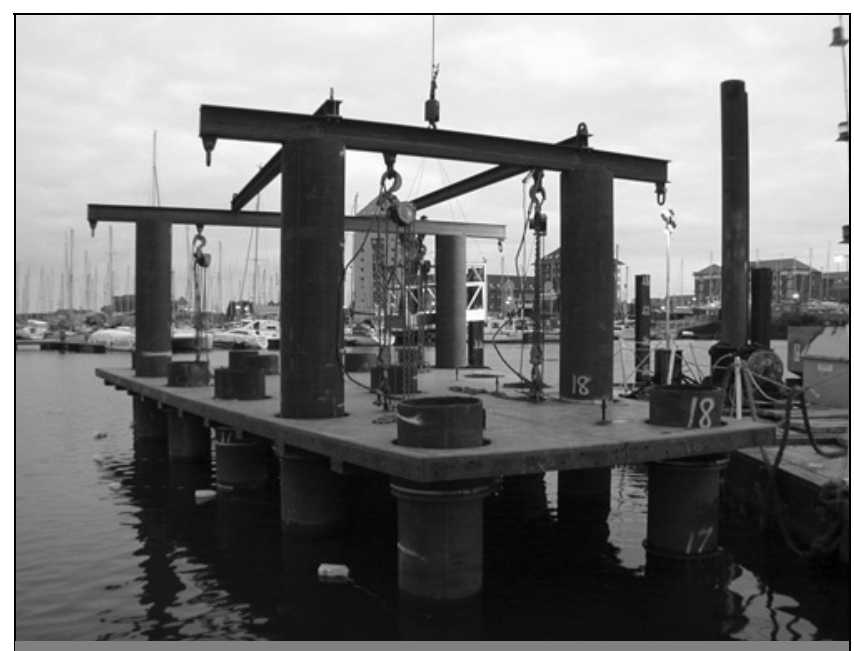

Fig. 17. Base of 'floating' steel cofferdam assembled at high level 


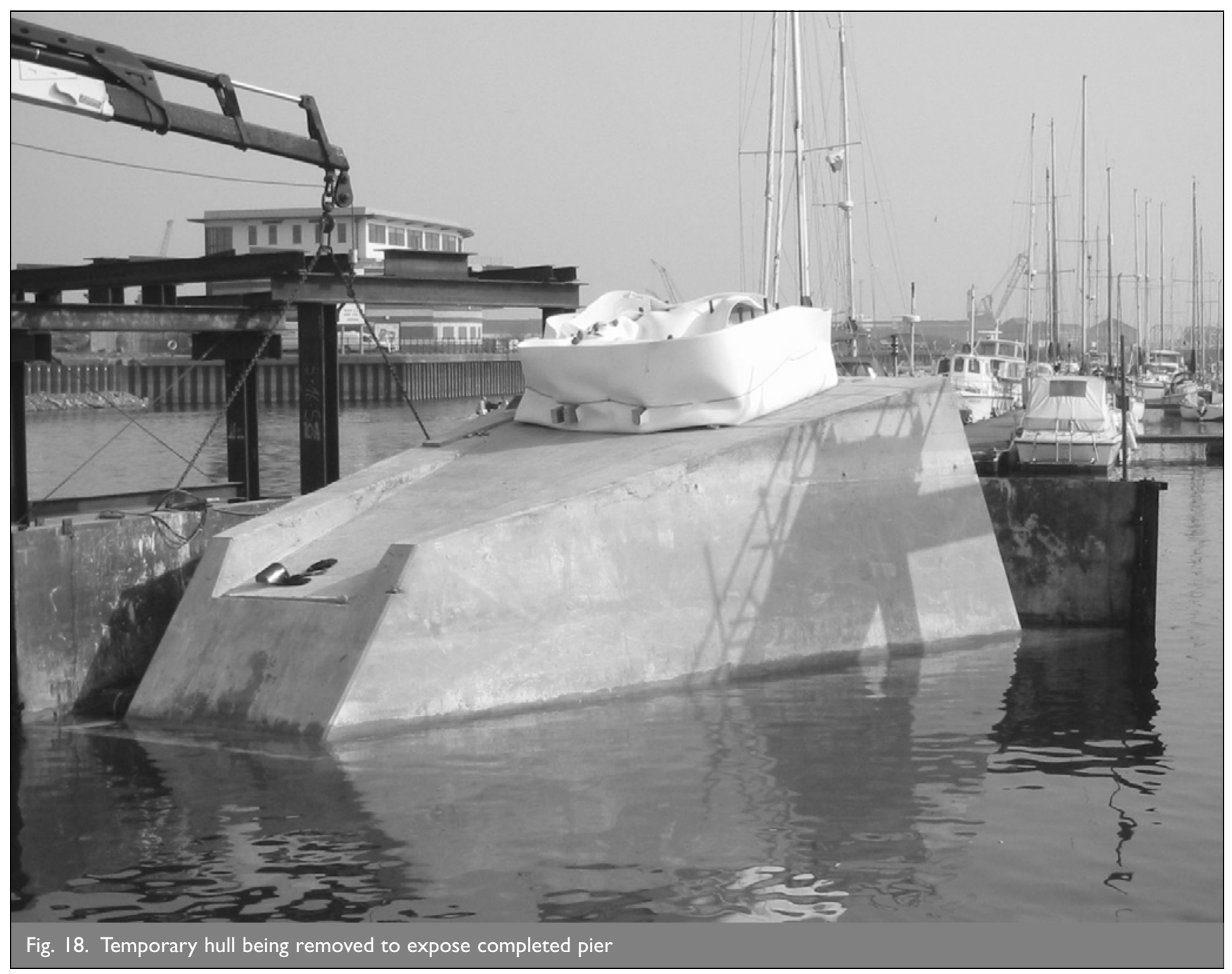

predicted. The cofferdam design also required careful consideration of the significant buoyancy forces generated. Although the cofferdam proved to a cost-effective method for constructing the main pier, some problems were encountered with installation of effective seals around the piles which could, with hindsight, be overcome with minor improvements to the gasket detail.

\section{CORROSION PROTECTION SYSTEMS}

The paint system for the Sail Bridge consisted of an aluminium metal spray $(100 \mu \mathrm{m})$ after blasting to $\mathrm{Sa} 3^{7}$ standard with an aluminium epoxy sealer, zinc phosphate primer, micaceous iron oxide (MIO) epoxy undercoat and an acrylic polysiloxane-finish coat. The minimum dry film thickness (DFT) is $360 \mu \mathrm{m}$. Because of the exposed environment and the difficulty of access the system was required to be maintenance-free in the first 12 years with major maintenance only after 25 years.

\section{CONCLUSIONS}

The Sail Bridge has become a recognisable icon for the city of Swansea. The bridge was designed and completed under very tight budget and programme constraints and stands as a good example of what can be achieved through the collaboration of engineers, architects and fabricators. It has been instrumental in attracting investment to the area and its cost is expected to be quickly offset by raising the profile of the Port Tawe redevelopment and regeneration project. It has already won several awards for excellence in design and implementation, including an ICE regional award, Civic Trust award, a structural steel design award and a Lord Mayor's design award. In addition the bridge has become a popular destination with the residents of Swansea.

The choice of materials and detailing took into account issues of economy and low maintenance in this harsh environment where access is extremely difficult. Maximum use of off-site prefabrication was made for reasons of economy and to ensure a high-quality finish. Minimum whole-of-life cost was a fundamental consideration as well as low initial cost, and this led to decisions regarding durable paint systems and the detailing of all components to facilitate inspection and maintenance.

\section{ACKNOWLEDGEMENTS}

The authors acknowledge the pivotal roles of the Welsh Development Agency (the client), Balfour Beatty Construction (main contractor), and others in achieving completion of these bridges. In particular, the considerable expertise and skills of Rowecord Engineering Ltd (steelwork contractor) and 
Wilkinson Eyre Architects (architects) are applauded with much gratitude.

\section{REFERENCES}

1. Her Majesty's Stationery Office. The Design Manual for Roads and Bridges (DMRB). HMSO, London.

2. British Standards Institution. The Design of Steel, Concrete and Composite Bridges. BSI, London, 1978-2000, BS 5400.

3. British Standards Institution. Code of Practice for Steel Bridges. BSI, London, 2000, BS 5400: Part 3.

4. Her Majesty's Stationery Office. BD49/01-Design Rules For Aerodynamic Effects on Bridges. HMSO, London, 2001.
5. Her Majesty's Stationery Office. BD37/01-Loads for Highway Bridges. HMSO, London, 2001.

6. Dallard P., Fitzpatrick A. J., Flint A. R., Le Bourva S., Low A., Ridsdill Smith R. M. and Willford M. The London Millennium footbridge. The Structural Engineer, 2001, 79, No. 22, 17-33.

7. British Standards Institution. Preparation of Steel Substrates Before Application of Paints and Related Products. Surface Roughness Characteristics of Blast-cleaned Steel Substrates. BSI, London, 1989, BS 7079-A1.

\footnotetext{
What do you think?

To comment on this paper, please email up to 500 words to the editor at journals@ice.org.uk

Proceedings journals rely entirely on contributions sent in by civil engineers and related professionals, academics and students. Papers should be 2000-5000 words long, with adequate illustrations and references. Please visit www.thomastelford.com/journals for author guidelines and further details.
} 